\title{
Reflexões sobre a materialidade escolar do Instituto Gentil Bittencourt em Belém do Pará: história, artefatos e arquitetura escolar
}

\author{
Reflections on the school materiality of the Instituto Gentil Bittencourt in Belém do Pará: history, \\ artifacts and school architecture
}

Reflexiones sobre la materialidad escolar del Instituto Gentil Bittencourt en Belém do Pará:

historia, artefactos y arquitectura escolar

Recebido: 24/09/2021 | Revisado: 25/09/2021 | Aceito: 30/09/2021 | Publicado: 03/10/2021

\author{
Marlucy do Socorro Aragão de Sousa \\ ORCID: https://orcid.org/0000-0002-6605-0292 \\ Universidade da Amazônia, Brasil \\ E-mail: marlucyaragao05@gmail.com \\ Maria do Socorro Pereira Lima \\ ORCID: https://orcid.org/0000-0002-4713-5514 \\ Universidade Federal do Pará, Brasil \\ E-mail: soclimma@yahoo.com.br
}

\begin{abstract}
Resumo
Este estudo discorre sobre a materialidade circulante no Instituto Gentil Bittencourt, em Belém do Pará, no início do século XX, período em que a cidade experimentou grandes transformações e conflitos promovidos pelos anseios de um projeto civilizatório de uma sociedade que utilizou a educação como ferramenta ideológica em suas dimensões prática, científica e política. Desta forma, nos empenhamos em investigar a educação no estado do Pará analisando os objetos e artefatos no campo da cultura material escolar a partir das instalações do Instituto Gentil Bittencourt. Objetivamos, portanto, analisar a presença dos objetos, artefatos, arquitetura e as práticas contidas na organização do cotidiano escolar no referido instituto, considerando a época de sua inauguração, em 1906 na cidade de Belém do Pará. Metodologicamente utilizamos dois momentos: primeiramente, a realização de um estudo exploratório permitindo identificar as fontes no Museu do Instituto Gentil Bittencourt, assim como na sua biblioteca; posteriormente, apresentamos breve articulação teórica. Assim, tomando como objeto de investigação a materialidade escolar do Instituto Gentil Bitencourt, temos a seguinte problemática: como a cultura material escolar se configura no espaço escolar com suas práticas e artefatos escolares? As análises realizadas para o desenvolvimento deste objeto, permiti-nos perceber como o desenvolvimento histórico, cultural e social do estado do Pará interferiu na materialidade do cenário educacional. Constatamos, ainda, que a utilização e disposição dos objetos e artefatos expostos na estrutura do edifício escolar analisado, bem como a as práticas escolares, revelam a organização das aulas e a formação moral, cívica e científica, voltadas para os preceitos pedagógicos estabelecidos nos regulamentos da instrução pública do Pará, em meados do século XX.
\end{abstract}

Palavras-chave: Cultura material escolar; Arquitetura escolar; Instituto Gentil Bittencourt; Pará.

\begin{abstract}
This study discusses the materiality circulating in the Gentil Bittencourt Institute, in Belém do Pará, in the beginning of the 20th century, a period in which the city experienced great transformations and conflicts promoted by the aspirations of a civilizing project of a society that used education as an ideological tool in its practical, scientific and political dimensions. Thus, we strive to investigate education in the state of Pará, analyzing objects and artifacts in the field of school material culture from the premises of the Gentil Bitencourt Institute. We aim, therefore, to analyze the presence of objects, artifacts, architecture and practices contained in the organization of everyday school life in the aforementioned institute, considering the time of its inauguration, in 1906 in the city of Belém do Pará. Methodologically, we used two moments: first, the carrying out an exploratory study allowing to identify the sources in the Museum of the Instituto Gentil Bittencourt, as well as in its library; later, we present a brief theoretical articulation. Thus, taking as an object of investigation the school materiality of the Gentil Bitencourt Institute, we have the following issue: how is school material culture configured in the school space with its school practices and artifacts? The analyzes carried out for the development of this object allowed us to perceive how the historical, cultural and social development of the state of Pará interfered with the materiality of the educational scenario. We also found that the use and arrangement of objects and artifacts displayed in the structure of the analyzed school building, as well as school practices, reveal the organization of classes and the moral, civic and scientific training,
\end{abstract}


focused on the pedagogical precepts established in the regulations of public education in Pará, in the mid-twentieth century.

Keywords: School material culture; School architecture; Gentil Bittencourt Institute; Pará.

\begin{abstract}
Resumen
Este estudio analiza la materialidad que circulaba en el Instituto Gentil Bittencourt, en Belém do Pará, a principios del siglo XX, período en el que la ciudad vivió grandes transformaciones y conflictos impulsados por las aspiraciones de un proyecto civilizador de una sociedad que utilizaba la educación. como herramienta ideológica en sus dimensiones práctica, científica y política. Así, nos esforzamos por investigar la educación en el estado de Pará, analizando objetos y artefactos en el campo de la cultura material escolar desde las instalaciones del Instituto Gentil Bittencourt. Pretendemos, por tanto, analizar la presencia de objetos, artefactos, arquitectura y prácticas contenidas en la organización de la vida escolar cotidiana en el mencionado instituto, considerando el momento de su inauguración, en 1906 en la ciudad de Belém do Pará. aprovechó dos momentos: primero, la realización de un estudio exploratorio que permitió identificar las fuentes en el Museo del Instituto Gentil Bittencourt, así como en su biblioteca; a continuación, presentamos una breve articulación teórica. Así, tomando como objeto de investigación la materialidad escolar del Instituto Gentil Bitencourt, tenemos la siguiente cuestión: ¿cómo se configura la cultura material escolar en el espacio escolar con sus prácticas y artefactos escolares? Los análisis realizados para el desarrollo de este objeto permitieron percibir cómo el desarrollo histórico, cultural y social del estado de Pará interfirió en la materialidad del escenario educativo. También encontramos que el uso y ordenamiento de los objetos y artefactos desplegados en la estructura del edificio escolar analizado, así como las prácticas escolares, revelan la organización de las clases y la formación moral, cívica y científica, enfocada en los preceptos pedagógicos establecidos en el normativa de la educación pública en Pará, a mediados del siglo XX.
\end{abstract}

Palabras clave: Cultura material escolar; Arquitectura escolar; Instituto Gentil Bittencourt; Pará.

\title{
1. Introdução
}

O presente artigo aborda sobre a materialidade escolar do Instituto Gentil Bittencourt, em Belém do Pará, no início do século XX, período em que a cidade experimentou grandes transformações e conflitos promovidos pelos anseios de um projeto civilizatório de sociedade que utilizou a educação como ferramenta ideológica em suas dimensões prática, científica e política. Desta forma, nos empenhamos em investigar a educação no estado do Pará, delimitando o estudo no campo da cultura material escolar. Desse modo, neste artigo, objetivamos, analisar a presença dos objetos, artefatos, arquitetura e as práticas contidas na organização do cotidiano escolar do Instituto Gentil Bittencourt, à época de sua inauguração, em 1906.

As discussões em torno da cultura material escolar no Brasil destacam diversas possibilidades de investigação, dentre as quais, aquelas que assim como esta, neste artigo, direcionam o olhar mais específico para a materialidade e suas contribuições para o processo de constituição das práticas e da formação dos sujeitos sociais.

Diferentes temáticas que evidenciam a materialidade da escola, fontes e opções teóricas e metodológicas, revelam as relações sociais, bem como a importância das práticas cotidianas no interior da escola, que por sua vez, constituem um cenário complexo de apropriação e compreensão da organização dos objetos, artefatos e rituais escolares, a s s i m c o m o seu funcionamento e os vetores desta relação.

Ao tratarmos da história da educação no Pará, no início do período republicano, assumimos o que propõe os estudos de Cesar Augusto Castro (2011) sobre o alargamento das fontes de pesquisa em história da educação e a produção de subjetividades através da análise da materialidade observada no interior do Instituto Gentil Bittencourt, de modo a verificar como a cultura material escolar se encontra representada nas categorias propostas por esse pesquisador, a saber: “indumentária; jogos e brinquedos; livros, material de higiene; material de limpeza; materiais visuais, sonoros e táteis para o ensino; mobília; organização/escrituração da escola; ornamentos; prédios escolares e utensílios da escrita" (Castro, 2011, p.13), dos quais nos interessa nesta pesquisa, os prédios, a mobília escolar e objetos escolares que compreendem a materialidade na história desta importante instituição de Ensino no estado do Pará, inaugurada como vitrine da educação paraense, segundo os princípios ideológicos republicanos. Desse modo, ao tomarmos como objeto de investigação a 
materialidade da escola, definimos a seguinte problemática para este estudo: como as práticas e artefatos da cultura material escolar se configuram no espaço do Instituto Gentil Bittencourt?

A partir desta multiplicidade de olhares sobre a cultura escolar e para avançar no entendimento de cultura material escolar do Instituto Gentil Bittencourt, abraçamos os conceitos de Margarida Felgueiras (2005), com intenção de sugerirmos uma mudança de foco, um desvio do olhar para outras dimensões do universo educacional. Do mesmo modo, Rosa Fátima de Souza (2007) traz como olhar novo deste universo, a arquitetura, o mobiliário, os utensílios, manuais didáticos e quaisquer outros materiais que não estejam no centro das discussões daquilo que se entende por ensino, mas, que também dão suportes às práticas como instrumentos mediadores da ação educativa.

Mediante os elementos expostos, a sistematização do estudo está estruturada da seguinte forma, além da introdução, primeiramente, discorremos sobre o percurso teórico e metodológico empreendido para o estudo proposto; posteriormente, discutimos a materialidade na arquitetura do Instituto Gentil Bitencourt e os objetos da cultura material; e, por fim, algumas considerações finais sobre a pesquisa que originou este artigo.

\section{Metodologia}

Este estudo parte das perspectivas da História da Educação com enfoque metodológico baseado na análise documental, que se reveste de interesse pelas descobertas e discussões acerca da história da educação em Belém do Pará e pesquisa sobre a materialidade escolar no início da Primeira República.

Nesta perspectiva, procuramos entender que a dimensão material da escola articula-se às concepções de cultura escolar e das práticas escolares. Estas articulações são importantes para a compreensão do funcionamento do interior da escola, a partir das análises dos usos e circulação dos materiais necessários para o seu funcionamento. Para esta compreensão, o diálogo se dá a partir das ideias de Diana Vidal, Margarida Felgueiras, Dominique Julia, Jean Claude Forquin, César Castro, Augustin Escolano, Rosa Fátima Souza e outros teóricos que discutem a relação cultura escolar, cultura material escolar e práticas escolares estabelecidas na produção e utilização dos dispositivos materiais.

Neste promissor campo de investigação que é a cultura material, é importante explorar o impacto que a materialidade tem na própria cultura, pois os artefatos não são apenas produtos, mas vetores de relações sociais. De acordo com Filgueiras (2005), por meio do conceito de cultura material, se olha a escola em sua globalidade. Ainda para esta autora, estudar a educação nos dias atuais, significa prestar atenção na densidade histórica do sistema educativo, nos contextos históricos de realização expressos numa cultura material, que simultaneamente traduzem as concepções de uma sociedade e manifesta as condições em que puderem ocorrer.

Mediante este conceito que imprime toda a ideologia de uma época compreendemos que os artefatos não seriam simples objetos, mas sim revelam as relações conflituosas ou pacíficas do contexto em que foram produzidos e utilizados (Julia, 2001). Portanto, ao tomarmos como análise a cultura material escolar no Instituto Gentil Bittencourt, temos como horizonte a percepção das suas articulações com o contexto histórico, cultural e social em que foi engendrado um novo modelo de educação que enfatizava como importantes os aspectos da civilidade, da nação e da moral.

\section{A Materialidade na Arquitetura do Colégio Gentil Bittencourt e os Objetos Escolares}

$\mathrm{Na}$ década final do século XIX, e m to d o o $\mathrm{Br}$ a si 1 , políticos e profissionais da educação passaram a considerar a criação de novos espaços para o funcionamento da educação de crianças. Defendiam a necessidade de prédios escolares construídos e configurados para a escola como um lugar especificamente destinado ao desenvolvimento do ensino. Esse momento coincide com a difusão do projeto republicano, que via na instrução pública o lugar para 
concretização de seu ideário educacional, pois era um momento em que a educação da criança passava a ser prioridade para os republicanos o que os levou, na época, a um grande investimento na educação primária, com destaque à construção de prédios escolares.

Segundo Rosa Fátima Souza (1998), a retórica arquitetônica dos edifícios escolares fez sintetizar todo o projeto político atribuído à educação popular. Ressalta esta autora, que na arquitetura escolar se encontram inscritas dimensões simbólicas e pedagógicas. Com isto, pode-se dizer que a escola como lugar, se define juntamente com a constituição do espaço social e cultural. Neste sentido, considerando o contexto político da época, o lugar de formação do cidadão republicano deveria ser percebido e compreendido como tal (Souza, 1998, p. 123-4).

Ainda de acordo com Rosa Fátima Souza (1998), a escola primária se destacou como uma das principais propagadoras dos valores republicanos, assim como foi depositado nela o poder de regeneração da nação. Por isso, a criação dos grupos escolares passou a ser símbolo desse novo projeto e implementação do novo regime. Este fato marcante da ideologia republica, merecia ser exibido e solenizado perante a sociedade. Neste cenário político, “esta nova modalidade de escola representou uma das mais importantes inovações do ensino, pois, tratava-se de uma nova organização administrativa e pedagógica, complexa e pautada nos princípios da racionalidade científica e na divisão do trabalho" (Souza, 1998, p. 16).

Cabe aqui ressaltar que a crença pelo poder redentor da educação, principalmente das grandes massas populares, levou a construção de um projeto civilizador que evidenciou a educação popular como uma necessidade política e social, tendo em vista a alfabetização dos sujeitos para a participação popular nas escolhas políticas do país. L o go, e ste preceito tornava a instrução primária indispensável para o combate ao analfabetismo e a consolidação do projeto republicano, como bem afirma Rosa Fátima:

A educação popular passa a ser considerada um elemento propulsor, um instrumento importante no projeto prometeico de civilização da nação brasileira. Neste sentido, ela se articula como o processo de evolução da sociedade rumo aos avanços econômico, tecnológico, científico, social, moral e político alcançados pelas nações mais adiantadas, tornando-se um dos elementos dinamizadores dessa evolução (Souza, 1998, p. 27).

Neste contexto de mudanças do novo regime, o Pará vislumbra o progresso com o boom da economia da borracha que se inicia ainda em 1870 e se estende aproximadamente até 1910. Trata-se de um período áureo de exploração e exportação do produto para grandes centros e diferentes países, que movimentava portos do mundo inteiro. O mundo direcionava o olhar para a belle époque ${ }^{l}$, simbolizada e concretizada pelo progresso e expansão da indústria gomífera, em que o estado do Pará teve sob o seu domínio até perder o monopólio para a Ásia.

O cenário social do Pará e da Amazônia, no período áureo da economia internacional do látex, foi atrelado aos investimentos em internacionalização da cultura, produzidos nas capitais da região norte do país, como representação de um padrão civilizado e burguês de práticas culturais e identidade presente no comportamento social dos sujeitos que viviam o cotidiano da cultura mundana em Belém do Pará. Conforme analisada por Coelho (2002), a representação do

\footnotetext{
${ }^{1}$ Este movimento, com aspirações de modernidade, apresentava tendências culturais que envolviam a arte, a moda, a postura, as construções. Características estas que se disseminaram no imaginário das pessoas e que passaram a ter concepção de que tudo relacionado à França era moderno, luxuoso e de muito bom gosto. Ver: Pimenta, A.S. F.,\& França, M. P. G.S. In: Educação e Instrução Pública no Pará Imperial e Republicano. 2015. p. 254
} 
homem civilizado, realizava-se por meio de uma linguagem polissêmica, cujos significados eram embrincados pelos requintes da modernização e nas condições reais e imaginárias por onde circulavam as riquezas, os bens de consumo e a cultura.

A forma do novo regime, a ideia republicana e sua materialidade no Pará, foram representadas com a construção de um monumento à República, com declarada finalidade pedagógica, no qual se revela a ideologia política e o poder exaltado pelo conjunto escultural que trazia a imagem como representação tanto ideológica quanto cultural. Neste contexto, o discurso pedagógico apresentado através da imagem, mostra-se como recurso das estratégias de poder, exaltando a celebração da modernidade republicana e do progresso.

Como resultado deste crescimento urbano e expansão geral da economia no estado do Pará, as medidas modernizadoras, impuseram restrições às camadas mais pobres da população, afastando-a cada vez mais do acesso aos bens materiais e sociais, principalmente do centro histórico que manteve suas características coloniais na edificação e organização, principalmente nas proximidades dos portos, garantindo a riqueza e a beleza da cidade. De acordo com Daou (2004), as novidades de objetos e materiais de construção chegavam de países da Europa como: Itália, Portugal e França, bem como a chegada de profissionais para trabalhar nas modificações do novo espaço de modernidade. Edifícios da administração pública, várias escolas, asilos, praças e muitos outros prédios que representavam a ordem e o reordenamento da cidade de Belém, constituíam as instituições de controle e reprodução social. No imaginário popular, Belém, com seus prédios vultuosos, era a cidade dos sonhos.

A monumentalidade das construções escolares promovida pelas reformas republicanas no estado do Pará, deu destaque para a importância da economia e do poder local. Era um período em que a economia da região amazônica se configurava como uma potencialidade para o estado, as edificações dos chamados palacetes de ensino revelaram o desejo do Estado em propagar as ações do governo paraense totalmente engajado no novo projeto nacional de educação.

Inaugurado em 1906, sendo elogiado e comparado, na época, como um palácio, sobretudo pela grandiosidade, mas também por suas condições higiênicas, o edifício do Instituto Gentil Bittencourt encontra suas características construtivas originalmente descritas no Esboço Histórico ${ }^{2}$ publicado no mesmo ano. Historiograficamente encontramos a sua gênese no ano de 1804, com D. Manoel Almeida Carvalho, quando este traz de uma viagem ao interior do estado algumas jovens índias e se compromete e abrigá-las e educá-las (Sabino, 2012). Nasce daí a prática de abrigar jovens índias em instituições asilares e de ensino em casas alugadas, uma prática que se mostrará bastante inadequada, contribuindo com a precarização das instalações físicas e dos serviços educacionais que marcará a história das instituições de ensino no Pará, até o alvorecer da República.

O edifício do Instituto Gentil Bittencourt, por apresentar simetria característica das edificações ecléticas, fora construído em formato de $\mathbf{E}$, recuado frontalmente da avenida Independência, que logo após os portões de entrada, recebia os visitantes com um frondoso jardim. Ao chegar á entrada principal, colocada logo após o jardim, acessa-se o corpo da edificação através de uma grande escada construída em mármore Carrara, com guarda-corpo abaulado também em mármore da mesma marca. Após a escadaria, um terraço dá acesso ao vestíbulo de entrada que, por sua vez, dá acesso a um segundo vestíbulo central que distribui o acesso dos usuários à edificação, através de uma circulação lateral que circunda os blocos da referida instituição.

Ao chegar na entrada principal encontra-se a edificação separada funcionalmente por pavimentos. Nas alas esquerda e direita, únicas a contar com 2 pavimentos habitáveis. No primeiro pavimento, encontra-se um abrigo com áreas destinadas às

\footnotetext{
${ }^{2}$ Publicação de Arthur Vianna, sob o título “O Instituto Gentil Bittencourt - Esboço histórico”. Produzido e encadernado pela tipografia do Instituto Lauro Sodré, em 1906.
} 
atividades pedagógicas, administrativas, recreativas e religiosas. O segundo pavimento abriga essencialmente a área de dormitórios, tanto das internas quanto da regente.

Das principais inovações propostas pela arquitetura eclética e que tentava resolver os problemas relacionados à higiene, estava a utilização do pé-direito duplo, um espaço medido entre o piso e o forro, que usualmente ficava em torno de 3 metros. Nas edificações escolares construídas no início da república, o pé-direito duplo chegava a passar dos 6 metros. No Instituto Gentil Bittencourt, o porão e os outros dois pavimentos mediam respectivamente 2,60, 6,30 e 7,00 metros de altura .

O porão, único a atender os 3 blocos, ventilado através de óculos, abertura na parte frontal das casas e igrejas do período colonial, contribuía com a iluminação e o arejamento destes ambientes. Nos pavimentos localizados acima do porão, alternavam-se sobre o posicionamento simétrico das janelas, uma característica comum das edificações ecléticas, frontões triangulares, em arco pleno e abatido, oriundos da arquitetura clássica greco-romana. Todos os detalhes da composição plástica da fachada principal da instituição, o que também incluía as platibandas para esconder os telhados, adotadas após a instalação de infraestrutura de coleta de água através de canaletas, o frontão principal, elemento marcante também de origem grecoromana e que normalmente recebia brasões comemorativos e encontrava-se posicionado sobre o frontispício, como pode ser percebido na fotografia apresentada na Figura 1.

Figura 01: Instituto Gentil Bittencourt.

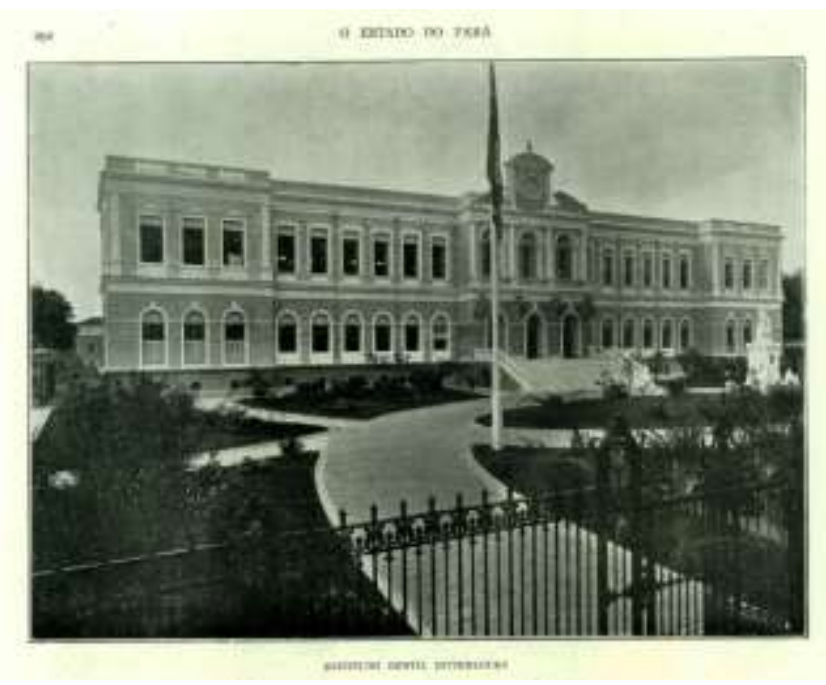

Fonte: Álbum oficial do Estado de 1908.

O número de vãos, portas e janelas, em suas dimensões elevadas, faceadas para as áreas externas e com a adoção das platibandas, o que excluía a utilização de beirais do telhado que projetavam sobras na parede, permitiam uma ampliação da ventilação interna e da iluminação natural dentro dos ambientes.

A partir dos vestíbulos de entrada, os alunos tinham acesso aos blocos através de um grande corredor lateral cuja estrutura superior era suportada por um conjunto de arcos. Estando esta área de trânsito e acesso a todos os blocos localizadas lateralmente as salas, o aproveitamento da ventilação e iluminação externa também eram potencializadas nas alas internas, conforme ilustra a Figura 2. 
Figura 2: Imagem da secretaria e ao fundo corredor iluminado naturalmente.

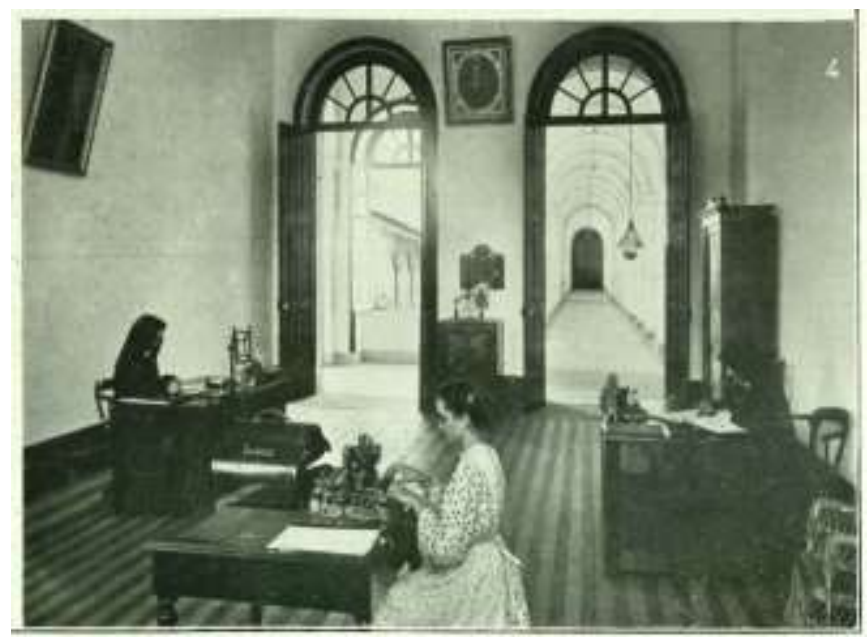

Fonte: Álbum oficial do Estado de 1908.

O grande refeitório localizado no bloco central, que tinha apenas um pavimento, continha quase $480,00 \mathrm{~m}^{2} \mathrm{e}$ organizava a quantidade total de alunas de forma satisfatória, dispondo de 2,40 $\mathrm{m}^{2}$ de área por aluna. O bloco central abrigava, além do refeitório, a despensa, copa, cozinha e uma sala de refeição para os irmãos ${ }^{3}$. Todo o bloco central fora construído, de ambos os lados, com janelas largas e que também faziam proveito da ventilação e iluminação natural, conforme podemos notar na Figura 3.

Figura 3 - Imagem do refeitório.

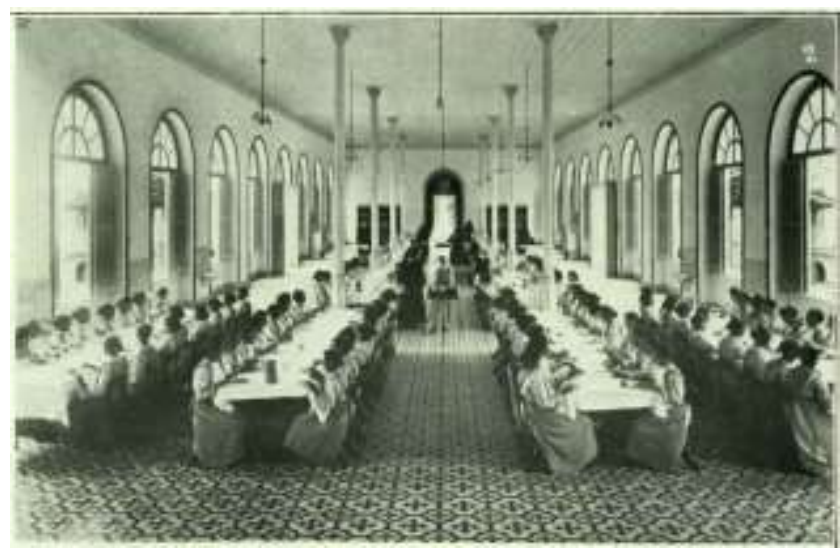

Fonte: Álbum oficial do Estado de 1908.

O segundo pavimento, acessível através de escadas em madeira localizadas no meio dos blocos direito e esquerdo, abrigava apenas amplos dormitórios, lavatórios, rouparias e banheiros em cada lado, ficando o aposento da regente localizado no centro dos dois blocos. O posicionamento das janelas, faceada com a área externa e exposta ao sol, também marcaram as características de salubridade dos espaços de dormir, conforme demonstra a Figura 4.

\footnotetext{
${ }^{3}$ Religiosos responsáveis pela gestão e funcionamento do colégio.
} 
Figura 4 - Imagem do dormitório.

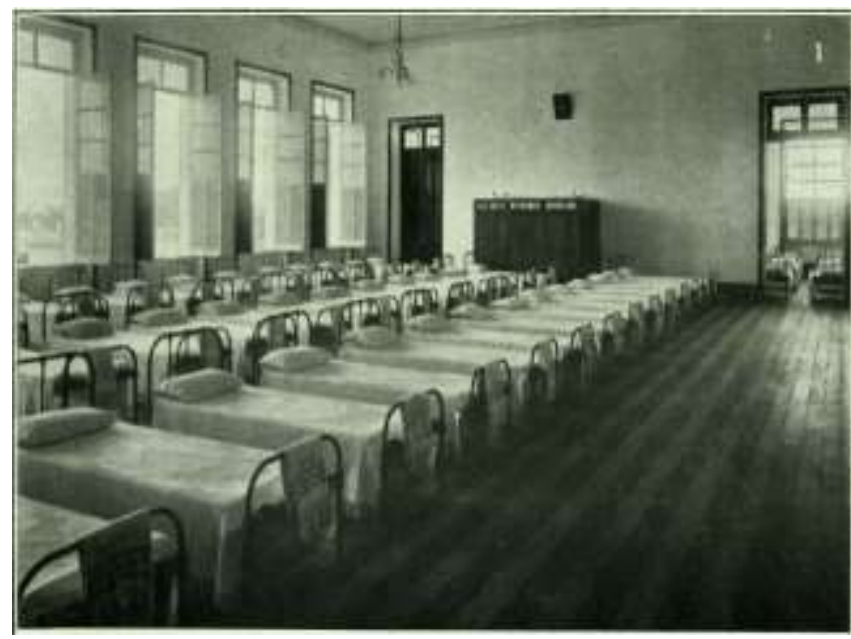

Fonte: Álbum oficial do Estado de 1908.

Atendendo ao Decreto n. 9.554, em 3 de fevereiro de 1886, a distribuição de água do Instituto Gentil Bittencourt, fora projetada para atender os três blocos de forma independente. Sobre cada bloco foi construído um reservatório de água de 5.000 litros que alimentava os banheiros dos blocos, tanto esquerdo quanto do direito e a área da cozinha no bloco central. A independência dos reservatórios garantia que a falta de água não seria um problema a comprometer a higiene da edificação e das educandas. Bacias em louça, chuveiros, sifões e tubulações niqueladas vindas da América do Norte, piso em mosaico de ladrilho hidráulico garantiam que a higiene do local não seria comprometida por vazamentos oriundos dos banheiros.

$\mathrm{O}$ tratamento do esgoto, projetado atendendo às normas e ao plano de desenvolvimento urbano da municipalidade, separava os resíduos sólidos oriundos das latrinas, da água vinda da cozinha e da água coletada pelas calhas dos telhados, permitindo uma adequada drenagem do terreno, impedindo o acúmulo de água e a proliferação de doenças que tinham como vetores os mosquitos e ratos.

Dois pátios internos situados entre o bloco central e os blocos laterais, observados na Figura 5, abrigavam atividades ao ar livre sob a sombra de dois coretos colocados um em cada lado, o que permitia a realização de atividades de fora das dependências do instituto, assim como a horta, localizada nos fundos do terreno, que permitia o viés prático do ensino e o desenvolvimento de atividades de cultivo.

Figura 5: Atividades ao ar livre nos pátios do Instituto Gentil Bittencourt.

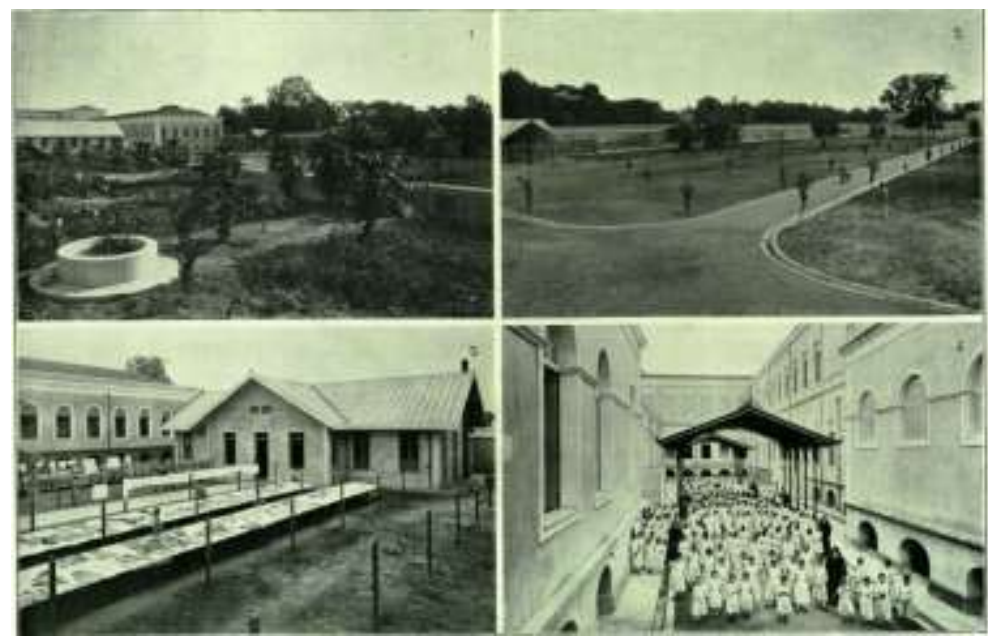

Fonte: Álbum oficial do Estado de 1908. 
Desse modo, o que se constata é que havia rigorosamente a preocupação com a construção do Instituto Gentil Bittencourt em seguir as normas éticas da construção civil, sem contar com a medidas dos espaços dos ambientes prevendo a utilidade de cada espaço, principalmente por se tratar inicialmente de uma instituição criada exclusivamente para jovens do gênero feminino, que demandava, à época, um cuidado para que as atividades pedagógicas que envolviam sala de aula e aulas práticas e lições de coisas, ou seja, atividades de formação previstas para a atuação feminina como esposa, mãe e prestadoras de serviços à igreja. Foi neste contexto social de mandas direcionadas ao papel da mulher nestas instituições que o Instituto Gentil Bittencourt foi criado, assim como para servir de vitrine para os propósitos republicanos no campo educacional.

\subsection{A organização do cotidiano escolar}

Esta subseção apresenta a imagem que se reporta ao interior de uma sala de aula no Instituto Gentil Bittencourt, início do século XX. A imagem da Figura 6 registra aspectos de uma cultura escolar direcionando o olhar mais específico para a materialidade que a compõe, a disposição da mobília e demais objetos que fazem parte do fazer pedagógico e das práticas estabelecidas para o desenvolvimento da aprendizagem. Uma cultura atrelada a práxis do cotidiano influenciada pelas proposições político-pedagógicas e assumidas pelos sujeitos que compunham o ambiente escolar. Com base no exposto, objetiva- se aqui identificar através das solicitações feitas pelas autoridades de ensino e professores, os materiais escolares que possibilitaram a organização do cotidiano e a construção da cultura escolar no estado do Pará, tendo com espaço de análise desses artefatos, o Instituto Gentil Bitencourt.

Figura 6: Sala de aula da instrução primária no Instituto Gentil Bittencourt.

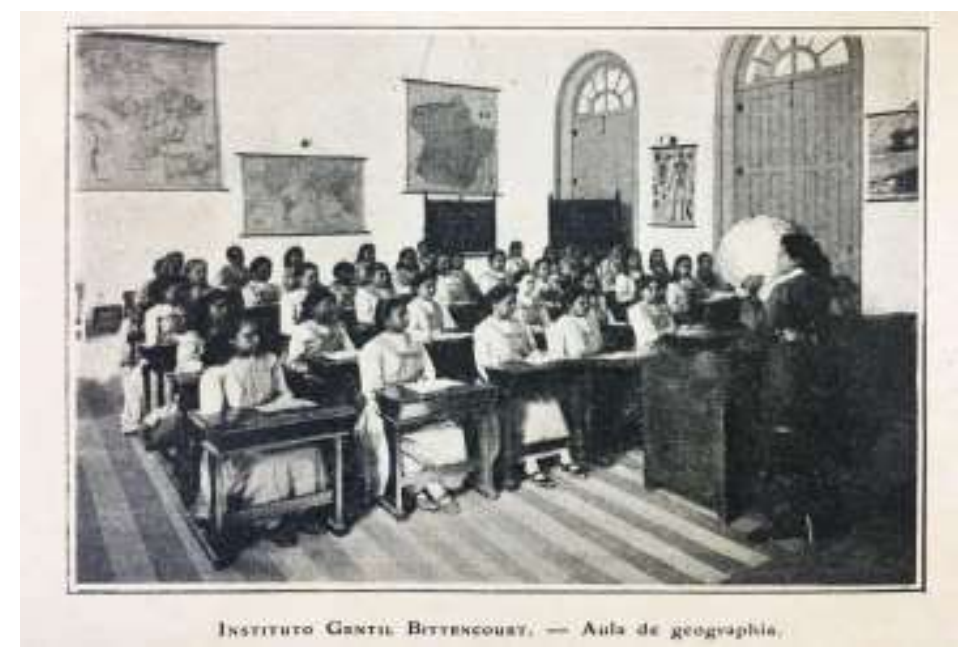

Fonte: Álbum do Pará (1908).

Ainda considerando o espaço da sala de aula do Instituto Gentil Bittencourt, pode-se entender a disposição dos diferentes objetos da cultura escolar dispostos nas salas de aula a partir do fato de ela ser destinada exclusivamente para meninas. Sendo isto, uma sala de aula formada somente por meninas, todas ficavam sentadas em carteiras individuais com pés de ferro, fixado ao piso de madeira e organizadas em filas. À frente das alunas, localizava-se a mesa construída em madeira de lei para a professora; na parte inferior da sala, há três mapas, entre eles o mapa do estado do Pará no canto superior direito e na lateral direita, quadros parietais, em destaque, o esqueleto humano. Além desses objetos, destacam- se, também, as amplas portas e janelas para uma boa ventilação e iluminação do espaço interior da sala. 
De acordo com as ideias de Escolano (2017) sobre a escola, pode-se considerar ser uma construção cultural complexa que produz uma diversidade de culturas, pois está inserida em contextos dotados de certas características sócio históricas, que se organiza e se transforma a partir de motivações que também são culturais. A transposição de valores e normas que se desenvolve no seio das instituições de formação, revelam o papel que a cultura escolar assume como uma função de apropriação ou adaptação dos saberes. Nesta dimensão, tomando como parâmetro tais constatações sobre a cultura, a própria escolar, mediante suas práticas, cria, codifica e transmite modelos culturais, que embora nem sempre visíveis, operam no funcionamento das instituições (Escolano, 2017, p. 118).

No processo de constituição dos sistemas nacionais de ensino e de desenvolvimento do capitalismo, vê-se um grande impulso na composição material da escola primária, ampliação esta que se consolidou em meados do século XIX. Neste período também se propagou a construção de prédios escolares, assim como se deu o surgimento de modernos materiais escolares, entre eles destaca-se o mobiliário escolar atendendo a novos modelos da moderna pedagogia propagada nos findos do XIX.

De acordo com Alcântara (2014), a difusão dos modelos se expandia pelas propagandas de novos objetos, tendo como alvo principal a escola. "As exposições foram disseminadoras de objetos de desejo", de civilidade e modernidade, pois esses espaços apresentavam o que havia de mais atual. A escola movimenta o mercado e faz com ele se adapte às demandas para atender tais necessidades, uma via de mão dupla que fortaleceu a indústria e aquisição pelo Estado de objetos necessários ao funcionamento das instituições educativas. (Alcântara, 2016, p. 81).

A aprovação de leis sobre a obrigatoriedade do ensino, a organização das aulas e a difusão de um modelo de educação que utilizasse em suas aulas práticas objetos e materiais adequados, põe a escola como um lugar de mercado consumidor atraente. Neste sentido, vê-se o fortalecimento do adequado provimento material da escola como: carteiras, bancos, mesas, quadros negros, livros e demais objetos para organização e funcionamento do cotidiano escolar. As reformas na instrução pública e a reorganização do ensino primário no Pará republicano, inclusão de disciplinas como Educação Moral, Cultura Pátria, Geografia Pátria, História Pátria e a Educação Física, elementos essenciais que de acordo com Veríssimo (1985) eram fundamentais para despertar o sentimento nacional e o amor à pátria, principalmente despertar nas crianças esse sentimento, as quais passavam a ser prioridade na proposta educacional dos republicanos. Por isso, destacamos aqui o uso dos compêndios, objetos e artefatos escolares tais como: o uso de mapas, globo terrestre, livros de história, geografia do Brasil e do Pará, para auxiliar na formação da sociedade brasileira e paraense, bem como as especificidades naturais de modo que os alunos conhecessem e se orgulhassem de sua terra.

As imagens do relógio, do sino e demais objetos expostos na Figura 7, representam a organização do tempo e do espaço no Instituto Gentil Bittencourt, assim como reforçam as hipóteses de que o estado do Pará se apropriou de uma mobília com moldes de requinte e elegância, colocando a instrução pública paraense no alto nível de aquisição de objetos para composição e organização do Ensino. 
Figura 7 - Objetos e mobiliário sinalizam a organização do tempo e espaço escolar.

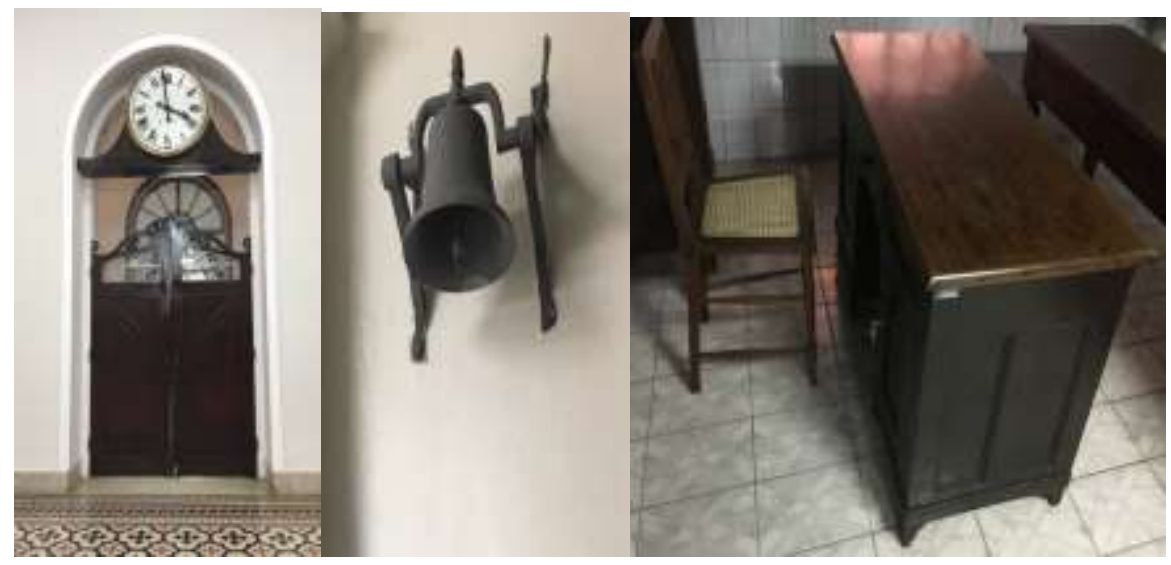

Fonte: Souza (2016), Arquivo pessoal - Disponível em: Instituto Gentil Bittencourt.

Como explicitado por Vidal \& Faria Filho (2000, p. 26) os instrumentos como os relógios, as campainhas, as sinetas passaram a fazer parte do material básico dos grupos escolares e, muitas vezes, das escolas isoladas, "cada hora precisa de aula ou de recreio será avisada em toque prolongado por uma campainha elétrica ou sineta, a cargo do director”. Assim, observa-se nos objetos apresentados nas imagens da figura 07, que fazem referencia ao Instituto Gentil Bittencourt, elementos representativos da cultura material escolar ao funcionamento, ordenamento e disciplina do tempo e do espaço escolar.

Vidal (2009) destaca ainda algumas questões principais quando se tematiza a cultura escolar nas investigações, tais como: "espaços escolares, tempos escolares, disciplinas escolares e cultura material escolar, compreendidos pela articulação em torno do funcionamento interno das instituições e as relações que estabelecia com a sociedade e cultura" (Vidal, 2009, p. 25). Neste sentido, a materialidade da escola se destacou como uma temática de análise, pois tem privilegiado o reconhecimento e as experiências dos sujeitos nos múltiplos espaços da escola, na construção de saberes, e com a variedade de objetos que circulam no interior do cotidiano escolar.

A materialidade diz respeito à sua constituição enquanto suporte que ocupa determinado espaço em determinado tempo, contribuindo para contextualizar as práticas em seus continentes materiais: dos manuais escolares aos cadernos, passando pelas imagens de quadros, gravuras e cartazes instrutivos expostos nas paredes, assim como outros objetos que compõem o cenário da sala de aula e seu entorno.

\section{Considerações Finais}

As análises realizadas para o desenvolvimento deste artigo acerca da cultura material escolar a partir dos objetos escolares compostos nos ambientes de aulas do Instituto Gentil Bittencourt, construído no período da Primeira República na capital do estado do Pará, nos permite perceber como o desenvolvimento histórico, cultural e social do estado interferiu na materialidade do cenário educacional, pois o governo paraense não poupou esforço e custos financeiros para construir uma instituição escolar de alto custo e padrão para colocar em prática um novo modelo de escola e uma nova pedagogia, chegando a se equiparar, inclusive, a outros estados mais desenvolvidos, como São Paulo e Rio de Janeiro, que despontavam como grandes polos de difusão da educação brasileira.

A pesquisa se inseriu num momento importante em que o país e especificamente o estado do Pará vislumbrava-se com a implantação e consolidação do regime republicano. Dessa forma, demandava-se o investimento e/ou fortalecimento de 
instituições de ensino, que fossem capazes de assegurar a materialização do projeto de desenvolvimento pautado na modernização dos espaços públicos, vinculados aos preceitos da moderna pedagogia anunciada na Primeira República.

O cenário político educacional no estado do Pará formou-se e esteve intimamente relacionado ao comércio do látex e o lucro que esse comércio gerava ao estado com a exploração da borracha, o que facilitou para uma nova organização da instrução pública, em especial a educação primária. Essa proposta foi vista pela elite política como a estrutura para a implantação do novo regime que iniciou no ano de 1890. Este lucrativo momento para o estado do Pará, permitiu as intervenções na modernização urbanística da capital, a renovação dos seus espaços num processo de embelezamento da cidade caracterizada como vitrines do progresso, expressando a realização dos anseios e desejos das elites políticas de se mostrarem progressistas e afinadas com o modelo de sociedade europeia.

Com o advento da República e o estado com poder econômico invejável, o estado do Pará inicia, na década final do século XIX, um processo de renovação dos esforços de construir uma sociedade engajada ao novo modelo econômico, dando resposta aos frequentes questionamentos presentes nos relatórios dos presidentes de província, que apontavam as condições de degradação da instrução pública no Pará.

Neste breve estudo, conseguimos avaliar como a condição social do período investigado, fomentou a evolução da legislação em saúde e higiene, que somado às novas necessidades educacionais deu origem às edificações escolares, materiais e práticas que consubstanciaram a cultura material escolar no início do período republicano no Pará, tendo inicialmente o Instituto Gentil Bitencourt como a representação desse modelo de escola e de pedagogia para difundir os ideais republicanos. A partir deste modelo, outros foram implantados, pelo menos até a decadência da borracha, quando o Pará perdeu o monopólio para a Ásia.

Ao tecer analise sobre o mobiliário escolar e a organização da materialidade da escola no Pará republicano, identificou-se que esta teve como horizonte a percepção das articulações dos materiais e objetos dispostos no ambiente escolar com os aspectos ligados ao contexto político, econômico, cultural e social. Em continuidade, o trabalho avança no sentido de analisar os meandros das relações históricas entre educação e cultura material no estado do Pará, suas percepções práticas e teóricas que influenciaram na formação da sociedade paraense. Chamamos atenção para o fato de que este tema envolve pesquisas que discutem a materialidade do universo escolar em seu percurso histórico e contemporâneo, por isso podemos afirmar que ainda há muito a ser discutido.

\section{Referências}

Alcantara, W. R. R. (2016). A transnacionalização de objetos escolares no fim do século XIX. Anais do Museu Paulista, São Paulo.

Bencostta, M. L. (2013). A noção de cultura material escolar em debate no campo de investigação da história da educação. Em C.A.Castro (Org.) Cultura material escolar: a escola e seus artefatos (MA, SP. PR, SC e RJ)- 1870/ 1925. São Luís: EDUFMA: Café \& Lápis.

Benito, A. E. (2018). Etnohistória e cultura material da escola: a educação nas exposições universais. Gaspar, V. L., \& Souza, G., \& Castro, C. Escritas $e$ possibilidades. Vitória, EDUFES.

Castro, C. A., \& Castellanos, S. L. V. (2018). A escola como vitrine: os objetos escolares nas exposições do trabalho no maranhão império. Gaspar, V. L \& Souza, G.; \& Castro, C. Escritas e possibilidades. Vitória, EDUFES.

Castro, C. \& Castellanos, S. L. V. (2018). A escola e seus artefatos culturais. São Luís: EDUFMA

Coelho N, J. T. (2014). A construção do sentido na arquitetura. Ed. Perspectiva, 6 ed. São Paulo.

Coelho, Alan Watrin (2006). A ciência do governar: positivismo, evolucionismo e natureza em Lauro Sodré. Dissertação (Mestrado). Programa de PósGraduação em História. UFPA.

Escolano Benito, A. (2017). A escola como cultura: experiência, memória e arqueologia. Campinas, sp: alínea.

Fabris, A. (1993). Arquitetura eclética no Brasil: o cenário da modernização. Anais Do Museu Paulista: História E Cultura Material, 1(1), 131-143.

https://doi.org/10.1590/S0101-47141993000100011

Faria, L. M. F. (2004). A cultura escolar como categoria de análise e como campo de investigação na história da educação. Revista Educação e Pesquisa, São Paulo, 30 (1) 139-159. 
Research, Society and Development, v. 10, n. 13, e18101321050, 2021

(CC BY 4.0) | ISSN 2525-3409 | DOI: http://dx.doi.org/10.33448/rsd-v10i13.21050

Felgueiras, M. L. (2005). Materialidade da cultura escolar: a importância da museologia na conservação/comunicação da herança educativa. ProPosições, 16(1).

Faria, L. M. F., \& Vidal, D.G (2000). Os tempos e os espaços escolares no processo de institucionalização da escola primária no Brasil. Rev. Brasileira de Educação, mai/jun/jul/ago. ?

Frago, A. V. (2005). Espaços, usos e funções: a localização e disposição física da direção escolar na escola graduada. História da Educação, arquitetura e espaço cultural. São Paulo: Cortez.

Frago, A. V., \& Escolano, A. (1998). Currículo, espaço e subjetividade: a arquitetura como programa. Rio de Janeiro: DP\&A.

Julia, D. (janeiro-junho, 2001). A Cultura Escolar como Objeto Histórico. Revista Brasileira de História da Educação, (1), 9-43.

Gaspar, V. L. \& Souza, G., \& Castro, C. A. (2018) (orgs.). Cultura material escolar em perspectiva histórica: escritas e possibilidades.Vitória, EDUFES .

Melo, C. N., \& França, M. P. S. G. S.A. (2014). História da educação no Pará. Belém: EDUEPA.

Moraes, F.T. (2011). A educação no Primeiro Governo de Lauro Sodré (1886-1897): os sentidos de uma concepção político-educacional republicana. Dissertação (Mestrado Acadêmico em Educação). Programa de Pós-Graduação em Educação. ICED/UFPA.

Sabino, E. B. (2012). A assistência e a educação das meninas desvalidas no colégio Nossa Senhora do Amparo na Província do Grão-Pará (1860-1889). Dissertação de Mestrado. Programa de Pós-Graduação em Educação. ICED/UFPA.

Segawa, H. (1998). Arquiteturas no Brasil - 1900-1990. Edusp. SP.

Sousa, C. M. P. (2015). Fragmentos da História da Educação no Pará no início do século XX; Instituto Gentil Bittencourt, origem, organização e concepções pedagógicas. Revista HISTEDBR, Campinas, 62 (1) 144-156.

Sousa, M.S.A. (2019). O mobiliário escolar na instrução pública primária do Pará: entre as "vitrines do progresso" e o "estado de ruínas". Tese. Programa de Pós-Graduação em Educação. ICED/UFPA.

Souza, R. F. (2007). História da Cultura Material Escolar: um balanço inicial. Marcus Levy Bencosta. (org.). Culturas escolares, saberes e práticas de ensino: itinerários históricos. São Paulo: Cortez.

Ribeiro, E. E H., \& Alves, J. J. (2015). Condições de criação da Escola de Engenharia do Pará: a valorização e formação científica dos En genheiros (1870 1931). Revista Brasileira de História da Ciência, Rio de Janeiro, 8 (1) 57-64.

Viana, A. (1906). O Instituto Gentil Bittencourt - Esboço histórico. Typ. e encadernação do Instituto Lauro Sodré. Pará.

Vidal, D. G. (2005). Cultura e Práticas Escolares. Culturas escolares. Estudo sobre práticas de leitura e escrita na escola pública primária (Brasil e França final do século XIX). Campinas: Autores Associados.

Vidal, D. G. (2009). No interior da sala de aula: ensaio sobre cultura e práticas escolares. Revista Currículo sem Fronteiras, 9 (1) $25-41$. 